\title{
Biweekly cetuximab in combination with FOLFOX-4 in the first-line treatment of wild-type KRAS metastatic colorectal cancer: final results of a phase II, open-label, clinical trial (OPTIMIX-ACROSS Study)
}

Julen Fernandez-Plana ${ }^{1}$, Carlos Pericay ${ }^{2}$, Guillermo Quintero ${ }^{3}$, Vicente Alonso ${ }^{4}$, Antonieta Salud ${ }^{5}$, Miguel Mendez ${ }^{6}$, Mercedes Salgado ${ }^{7}$, Eugeni Saigi ${ }^{8}$, Luis Cirera ${ }^{9^{*}}$ on behalf of the ACROSS Study Group

\begin{abstract}
Background: This phase II study aims to evaluate the efficacy and safety of biweekly cetuximab in combination with oxaliplatin, leucovorin, and fluorouracil (FOLFOX-4) as first-line treatment of metastatic wild-type KRAS colorectal cancer.

Methods: Previously untreated patients with wild-type KRAS tumours received biweekly cetuximab $\left(500 \mathrm{mg} / \mathrm{m}^{2}\right.$ on day 1) plus FOLFOX-4 (oxaliplatin $85 \mathrm{mg} / \mathrm{m}^{2}$ on day 1, leucovorin $200 \mathrm{mg} / \mathrm{m}^{2}$ on days 1 and 2, and fluorouracil as a $400 \mathrm{mg}$ / $\mathrm{m}^{2}$ bolus followed by a 22-hour $600 \mathrm{mg} / \mathrm{m}^{2}$ infusion on day 1 and 2). Treatment was continued until disease progression, onset of unacceptable toxicities, metastases surgery, or discontinuation request. The primary endpoint was ORR.

Results: The intention-to-treat population included 99 patients with a median age of 64.1 years (range, 34-82). The ORR was $60.6 \%$ (95\% Cl, 50.3\% to 70.3\%). The median follow-up was 17.8 months; the median OS and PFS were 20.8 and 10.1 months, respectively. Metastases from colorectal cancer were surgically resected in 26 (26.3\%) patients, with complete resection achieved in 18 (69.2\%) patients. Median PFS and OS in patients undergoing metastatic resection were 12.6 and 29.5 months, respectively. The most common grade 3-4 toxicities were neutropenia (32.3\%), acne-like rash (15.2\%) and diarrhoea (11.1\%).

Conclusions: The efficacy of the biweekly combination of cetuximab with FOLFOX-4 in patients with wild-type KRAS tumours supports the administration of cetuximab in a dosing regimen more convenient for patients and healthcare providers. The activity of the biweekly administration is similar to what has been reported for the weekly regimen. Reported toxicity was also consistent with the known toxicity profile of weekly cetuximab.
\end{abstract}

Trial registration: EudraCT Number 200800690916

Keywords: Cetuximab, FOLFOX-4, Metastatic colorectal cancer, First-line, Wild-type KRAS

\section{Background}

Colorectal cancer (CRC) is the second most common cancer and the second leading cause of cancer mortality in Europe [1]. The major cause of death in CRC are distant metastases [2]. It is expected that approximately $25 \%$ of patients diagnosed with CRC present with metastasis at initial diagnosis, whereas approximately $50 \%$ of

\footnotetext{
* Correspondence: Icirera@mutuaterrassa.es

${ }^{9}$ Hospital Universitario Mútua Terrassa, Plaça del Dr. Robert N5, Terrassa, Barcelona 08221, Spain

Full list of author information is available at the end of the article
}

patients will develop metastatic CRC (mCRC) during the follow-up [3].

Significant advances in the treatment of mCRC have been made within the last years after decades of only modest progress with 5-fluorouracil (5-FU) monotherapy. Consequently, the combination of oxaliplatin or irinotecan with 5-FU have markedly improved treatment outcomes [4-6]. Furthermore, the addition of targeted therapies to conventional mCRC chemotherapy regimens has resulted in further improvement of efficacy results [7]. 
Cetuximab, a chimeric monoclonal antibody that targets the epidermal growth factor receptor (EGFR), is currently a component of the standard of care for mCRC [8]. Two randomised clinical trials demonstrated the clinical efficacy of adding weekly cetuximab to irinotecan- or oxaliplatin-based chemotherapy regimens in the first-line treatment of patients with wild-type KRAS mCRC [9-12].

The standard cetuximab dosing regimen, both as a monotherapy and in combination with chemotherapy, involves an initial intravenous infusion of $400 \mathrm{mg} / \mathrm{m}^{2}$ with subsequent weekly doses of $250 \mathrm{mg} / \mathrm{m}^{2}$. In contrast, a biweekly dosing schedule -every 14 days- would offer several advantages in terms of convenience and a more economical use of healthcare resources [13]. Moreover, these benefits would be enhanced in mCRC treatment regimens as standard first-line chemotherapy regimens approved for use in combination with cetuximab in wild-type KRAS mCRC, such as oxaliplatin, 5-FU infusion and leucovorin (FOLFOX) or irinotecan plus 5-FU infusion and leucovorin (FOLFIRI), are already administered in a biweekly basis.

The feasibility of a biweekly cetuximab administration schedule was demonstrated in a two-part phase I doseescalation study [14]. This study demonstrated that cetuximab can be safely administered as single agent or in combination with FOLFIRI at doses between 400 and $700 \mathrm{mg} / \mathrm{m}^{2}$ in a biweekly schedule, and $500 \mathrm{mg} / \mathrm{m}^{2}$ was established as the recommended dose on the basis of pharmacokinetic exposure data [14]. Furthermore, data provided by several studies involving a combined regimen of cetuximab and irinotecan support the hypothesis that safety and efficacy of a biweekly schedule are similar to a weekly schedule [15-17].

Seeking to increase convenience for patients and healthcare providers, this phase II study was designed with the aim to evaluate the efficacy and safety of biweekly cetuximab in combination with FOLFOX-4 in the first-line treatment of wild-type KRAS mCRC.

\section{Methods}

\section{Study design}

This multicentre, single-arm, open-label, phase II clinical trial was carried out in 15 Spanish centres (EudraCT Number: 2008-006909-16). The local authorities and ethic committees or institutional review boards at each participating centre approved the study protocol and its amendments. The study was conducted in accordance with the ethical principles of the Declaration of Helsinki. All patients provided written informed consent.

\section{Patients}

Inclusion criteria were an age of 18 years of older, histologically confirmed colorectal carcinoma, wild-type KRAS tumours, first occurrence of metastatic disease, at least one radiologically measurable lesion, a life expectancy of $\geq 12$ weeks, an Eastern Cooperative Oncology Group (ECOG) Performance Status $\leq 1$, and adequate hematologic, hepatic and renal function. Patients with prior exposure to anti-EGFR therapy or chemotherapy for metastatic disease (with the exception of oxaliplatin if completed $\geq 6$ months prior to inclusion) were not eligible for inclusion.

\section{Study treatment}

Patients received a biweekly intravenous (IV) infusion of cetuximab $\left(500 \mathrm{mg} / \mathrm{m}^{2}\right.$ on day 1$)$ followed by FOLFOX4 (2-hour oxaliplatin $85 \mathrm{mg} / \mathrm{m}^{2}$ infusion on day 1 in tandem with a 2-hour leucovorin $200 \mathrm{mg} / \mathrm{m}^{2}$ infusion on day 1 and 2, and 5 -FU as a $400 \mathrm{mg} / \mathrm{m}^{2}$ bolus followed by a 22 -hour $600 \mathrm{mg} / \mathrm{m}^{2}$ infusion on day 1 and 2). Cetuximab was administered over 2 hours in the first cycle, over 1.5 hours in the second cycle and over 1 hour thereafter. Appropriate prophylactic medication was administered to prevent the occurrence of acute hypersensitivity reactions before each cetuximab administration.

Protocol dose modifications were permitted in the event of predefined toxic effects related to chemotherapy or cetuximab [17]. In the event of unacceptable toxicity due to 5-FU/leucovorin, oxaliplatin, or cetuximab, the agent responsible could be discontinued and the patient could continue with the other study medications. However, protocol modifications did not allow the maintenance of oxaliplatin as a monotherapy or in combination with cetuximab. Treatment was continued until disease progression, onset of unacceptable toxic effects, a patient/physician request to discontinue, or surgery for metastases.

\section{Study assessments}

Pre-treatment evaluations included the determination of KRAS mutation status. Mutation analysis was performed centrally at the Hospital Universitario Mútua Terrassa. Tumour DNA was extracted from formaldehyde-fixed paraffin-embedded tissues. Mutant KRAS in exon 2 was detected using a validated KRAS mutation kit (DxS LTD., Manchester UK) that identifies seven somatic mutations located in codons 12 and 13 using allele-specific real-time PCR. The analysis was performed in an ABI Prism 7300 instrument (Applied Biosystems).

Computed tomography $(\mathrm{CT})$ or magnetic resonance imaging (MRI) was performed at baseline, every 8 weeks during the first 6 months of the study, and every 12 weeks thereafter until disease progression. Adverse events were collected throughout the study period. All adverse events recorded were graded according to the Common Toxicity Criteria of the National Cancer Institute (CTC-NCI) version 3.0. 


\section{Statistical analysis}

The primary endpoint of the study was the objective response rate (ORR) defined according to the Modified Response Criteria in Solid Tumours (RECIST 1.1) [18]. Secondary endpoints included progression-free survival (PFS), duration of response, overall survival (OS) and toxicity profile of biweekly cetuximab in combination with FOLFOX-4. Patients who underwent surgery for metastases were censored at the date of surgery in the PFS analysis. Median PFS and OS following metastasectomy were also assessed for this group of patients. The cut-off date for collection of survival data was November $19^{\text {th }}, 2012$.

A sample size of 98 patients was calculated to detect a 95\% confidence interval (CI) for the ORR of $50-70 \%$, assuming an estimated rate of $60 \%$ according to previous studies and an anticipated $10 \%$ of patient loss to follow-up [9].

The intention to treat population (ITT) included all patients that received at least one dose of the combination chemotherapy (four drugs) and had at least one radiological assessment at 8 weeks. Safety analysis was conducted in the group of patients that received at least one dose of any of the four drugs (oxaliplatin, leucovorin, 5-FU or cetuximab).

Numerical variables were summarized as mean and standard deviation (SD). For categorical variables, absolute and relatives frequencies were calculated. Time-toevent variables were analysed using the Kaplan-Meier method. Relative dose intensity (RDI) was calculated by dividing the dose intensity of the administered regimen by the dose intensity of the drug in the standard planned regimen. Data analysis was performed using the Statistical Analysis System version 9.2 (SAS 9.2).

\section{Results}

\section{Patient disposition and baseline characteristics}

From July 2009 until December 2011, 101 patients were included in the study. Two patients immediately withdrew their consent. The ITT population consisted of 99 patients. Safety analysis was carried out on the 99 patients who received at least one dose of any component of the study treatment. Demographic and clinical characteristics at baseline are shown in Table 1. Median age of the patients was 64.1 years (range: $34-82$ years). Thirty-five patients presented with metastases limited to the liver. The median duration of follow-up was 17.8 months.

\section{Efficacy}

The best confirmed ORR was $60.6 \%$ (95\% CI, $50.3 \%$ to 70.3\%) (4 complete and 56 partial responses) (Table 2). Thirty patients $(30.3 \%)$ had stable disease. Therefore, the disease control rate (DCR) was $90.9 \%$ (95\% CI, $83.4 \%$ to $95.8 \%)$. In the 60 patients with a partial or complete
Table 1 Demographic and clinical data at baseline in the intention-to-treat population

\begin{tabular}{|c|c|}
\hline Characteristic & $\mathrm{N}=99$ \\
\hline Male, n (\%) & $66(66.7)$ \\
\hline White/Caucasian ethnicity, n (\%) & $98(99.0)$ \\
\hline Median age, years (range) & $64.1(34-82)$ \\
\hline \multicolumn{2}{|l|}{ ECOG status, $n(\%)$} \\
\hline 0 & $51(51.5)$ \\
\hline 1 & $48(48.5)$ \\
\hline \multicolumn{2}{|l|}{ Tumor status at diagnosis, $\mathrm{n}(\%)$} \\
\hline $\mathrm{T} 1$ & $1(1.0)$ \\
\hline T2 & $6(6.1)$ \\
\hline T3 & $43(43.4)$ \\
\hline T4 & $25(25.3)$ \\
\hline Unknown & $24(24.2)$ \\
\hline \multicolumn{2}{|l|}{ Node status at diagnosis, n (\%) } \\
\hline No & $22(22.2)$ \\
\hline N1 & $24(24.2)$ \\
\hline N2 & $25(25.3)$ \\
\hline Unknown & $28(28.3)$ \\
\hline \multicolumn{2}{|l|}{ Metastases status at diagnosis, n (\%) } \\
\hline MO & $21(21.2)$ \\
\hline M1 & $76(76.8)$ \\
\hline Unknown & $2(2.0)$ \\
\hline \multicolumn{2}{|l|}{ Primary tumor site, n (\%) } \\
\hline Colon & $59(59.6)$ \\
\hline Rectum & $40(40.4)$ \\
\hline \multicolumn{2}{|l|}{ Metastases sites*, n (\%) } \\
\hline Liver & $87(87.9)$ \\
\hline Lung & $39(39.4)$ \\
\hline Lymph nodes & $27(27.3)$ \\
\hline Other & $17(17.1)$ \\
\hline \multicolumn{2}{|l|}{ Prior therapy, $\mathrm{n}(\%)$} \\
\hline Adjuvant chemotherapy (FOLFOX) & $9(9.1 \%)$ \\
\hline Neoadjuvant chemo-radiotherapy for rectal cancer & $7(7.1 \%)$ \\
\hline Surgery & $48(48.5 \%)$ \\
\hline
\end{tabular}

Abbreviations: ECOG Eastern Cooperative Oncology Group, ITT Intention to treat, Q1-Q3 Interquarile range.

*A patient may had metastases in more than one organ.

response, median time to onset of response was 1.9 months and median duration of response was 8.6 months.

Objective disease progression was observed in $68 \mathrm{pa}-$ tients. Median PFS was 10.1 months (Q1-Q3, 6.5-14.8) (Table 2; Figure 1). Time to progression, defined as time from the first treatment administration to the first objective disease progression in the 60 patients who had a complete/partial response, was 10.4 months (Q1-Q3, 6.8-17.9). At the time of data collection cut-off there were 57 deaths (57.6\%). The median OS was 20.8 months (Q1-Q3, 11.6-32.8) (Table 2; Figure 2). 
Table 2 Efficacy in the intention-to-treat population

\begin{tabular}{|c|c|}
\hline Variable & $\begin{array}{l}\text { ITT population } \\
\mathrm{N}=99\end{array}$ \\
\hline \multicolumn{2}{|l|}{ Response, n (\%) } \\
\hline Complete response & $4(4.0)$ \\
\hline Partial response & $56(56.6)$ \\
\hline Stable disease & $30(30.3)$ \\
\hline Progressive disease & $5(5.1)$ \\
\hline Not available & $4(4.0)$ \\
\hline ORR, \% (95\% Cl) & 60.6 (50.3 to 70.3$)$ \\
\hline $\mathrm{DCR}, \%(95 \% \mathrm{Cl})$ & 90.9 (83.4 to 95.8$)$ \\
\hline \multicolumn{2}{|l|}{ Progression-free survival } \\
\hline Progression event, n (\%) & $68(68.7)$ \\
\hline $\begin{array}{l}\text { Months of progression-free } \\
\text { survival, median (Q1-Q3) }\end{array}$ & $10.1(6.5-14.8)$ \\
\hline \multicolumn{2}{|l|}{ Overall survival } \\
\hline Death, n (\%) & $57(57.6)$ \\
\hline Months of overall survival, median (Q1-Q3) & $20.8(11.6-32.8)$ \\
\hline
\end{tabular}

Abbreviations: $C l$ confidence interval, $D C R$ disease control rate, $I T T$ intention-totreat, ORR objective response rate, $Q 1-Q 3$ Interquarile range.

Twenty-six patients (26.3\%) underwent surgery for liver metastases, with complete surgical resection (R0) observed in $18(18.2 \%)$ patients. The median PFS and OS after surgical resection of metastases were 12.6 months and 29.5 months, respectively. Twenty-one patients $(80.8 \%)$ who underwent surgery for metastases received adjuvant chemotherapy. Thirteen of the 21 patients continued with cetuximab-containing regimens after surgery.

\section{Treatment exposure}

The median duration of cetuximab treatment was 20.9 weeks (range: 1-148). The median cumulative dose of cetuximab was $4659.4 \mathrm{mg} / \mathrm{m}^{2}$ and the median intensity of dose per cycle was $447.1 \mathrm{mg} / \mathrm{m}^{2}$; therefore the median cetuximab dose used in this study was similar to the recommended $500 \mathrm{mg} / \mathrm{m}^{2}$ dose. Consequently, the median relative dose intensity was $89 \%$, with a total of eighty-two patients $(82.8 \%)$ receiving $\geq 80 \%$ relative dose intensity (RDI) of cetuximab. Thirty-nine patients $(39.4 \%)$ had at least one cetuximab dose reduction. Delays in cetuximab dosing were mostly due to skin reactions. As for chemotherapy, the median duration of oxaliplatin and 5-FU treatment was 18.3 weeks (range: 1-46) and 22.9 weeks (range: 1-83), respectively. A RDI $\geq 80 \%$ was achieved in 58 patients (58.6\%) for oxaliplatin and in 55 patients (55.6\%) for 5-FU. Two or more lines of treatment were received by $62.6 \%$ of patients, whereas $5.1 \%$ of patients underwent surgery and did not receive additional lines of treatment postsurgery.

\section{Safety}

Adverse events (AEs) of any grade occurring in at least $10 \%$ of patients and grade 3 or 4 AEs occurring in at least $2 \%$ of patients are summarized in Table 3 . Seventyseven patients $(77.8 \%)$ presented at least one grade 3 or $4 \mathrm{AE}$. The most common grade 3 or 4 AEs were neutropenia (32.3\%) and diarrhoea (13.1\%).

For grade 3 or 4 special adverse events, $15.2 \%$ patients presented with acne-like rash, $6.1 \%$ presented with nail toxicity (this special event category included the preferred terms nail toxicity and paronychia) and no patient presented with infusion-related reactions (this special event category included the preferred terms "infusion related reaction" and "pyrexia"). Hypomagnesemia was reported in only one patient (grade 4). Cetuximab was discontinued in 33 patients (33.3\%), oxaliplatin was discontinued in 41 patients $(41.4 \%)$ and 5 -FU was discontinued in 25 patients $(25.3 \%)$ due to adverse events.

Disease progression was the primary cause of death (91.2\% of deaths). Two patients died due to an unrelated $\mathrm{AE}$ and one patient died due to a related AE. This patient presented with pulmonary fibrosis that was considered related to oxaliplatin and/or cetuximab.

\section{Discussion}

This study showed that the efficacy of biweeklyadministered cetuximab in combination with FOLFOX-4 is similar to what has been reported for the standard weekly cetuximab dosing regimen as first-line treatment of wild-type KRAS mCRC. The ORR obtained in the present study (61\%) was similar to the figure reported in a previous phase II study with a weekly administration of cetuximab in combination with FOLFOX-4 [10]. A similar ORR was also obtained (62\%) in the biweekly cetuximab arm of the recently published randomised study performed by the Central European Co-operative Oncology Group (CECOG) [19]. In the weekly cetuximab arm of that phase II study, a lower ORR was obtained (53\%). The CECOG trial was not powered to establish non-inferiority of biweekly administration versus weekly administration of cetuximab, so further studies would be needed to confirm their findings.

The median PFS (10.1 months) observed is also in line with the 8.3 months and 9.5 months reported in previous studies with weekly cetuximab combined with FOLFOX-4, and very similar to the figure obtained in the biweekly arm of the CECOG trial (9.2 months) $[10,19]$. It was also slightly longer than the range of 8.4-9.1 months reported for standard weekly cetuximab in combination with other oxaliplatin-based chemotherapy regimens in patients with wild-type KRAS mCRC [7,20]. Although the short median follow-up of our study does not permit us to draw 


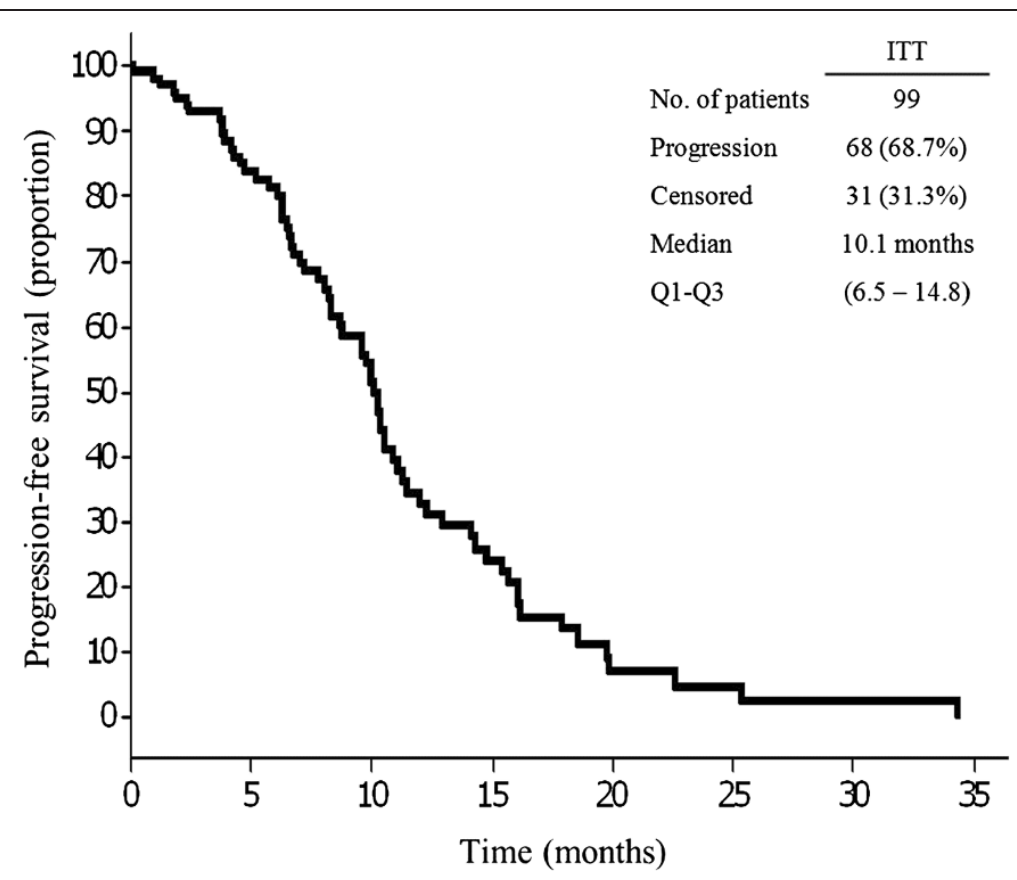

Figure 1 Kaplan-Meier plot for progression-free survival in the intention to treat (ITT) population.

definitive conclusions regarding OS, the median time obtained (20.8 months) was slightly shorter but consistent with the median OS reported for standard weekly cetuximab in combination with FOLFOX-4 and in the biweekly arm of the CECOG trial $[10,19]$.
Complete surgical resection of colorectal liver metastases is potentially curative and provides clear survival benefits in patients with disease confined to the liver. Within this context, 35 out of 99 patients in our study presented with only liver metastases. $26.3 \%$ of patients

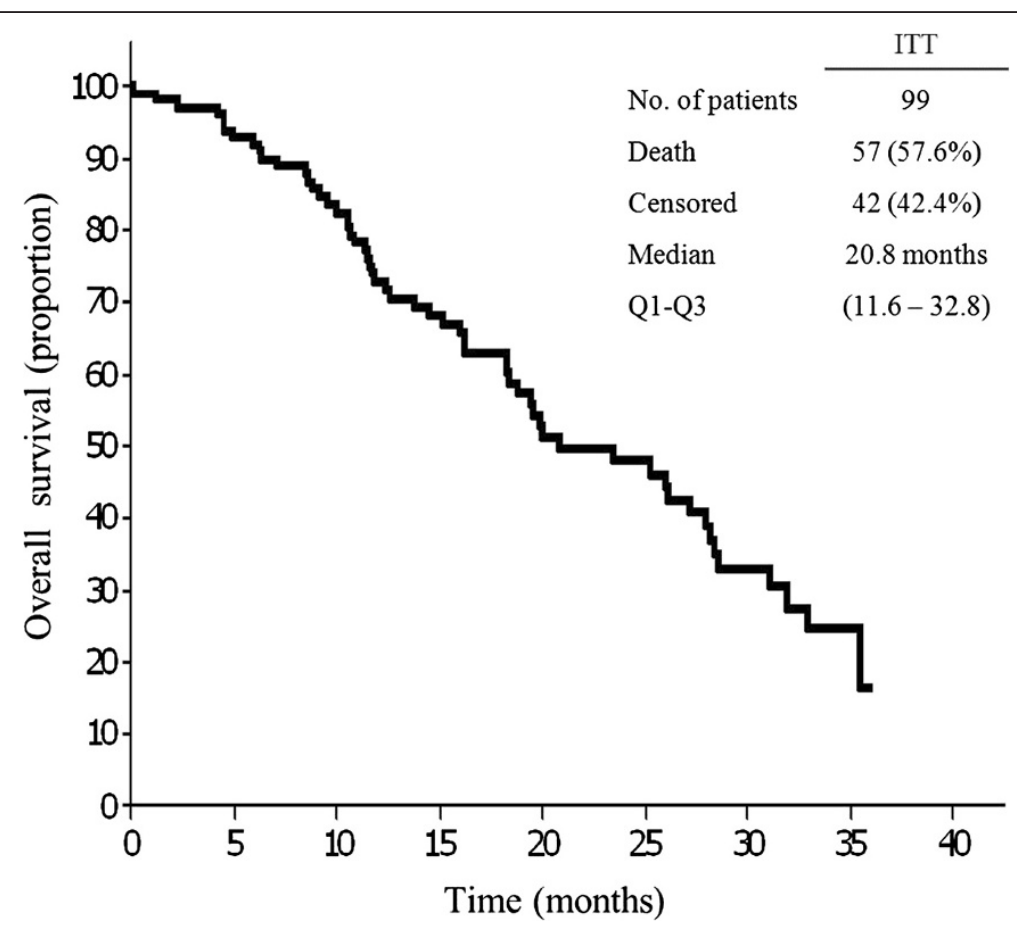

Figure 2 Kaplan-Meier plot for overall survival in the intention to treat (ITT) population. 
Table 3 Adverse events

\begin{tabular}{|c|c|c|}
\hline Adverse event & Any grade & Grade 3 or 4 \\
\hline Any adverse event* & $97(98.0 \%)$ & $77(77.8 \%)$ \\
\hline \multicolumn{3}{|l|}{ Blood and lymphatic system disorders } \\
\hline Anaemia & $11(11.1 \%)$ & $2(2.0 \%)$ \\
\hline Febrile neutropenia & $6(6.1 \%)$ & $5(5.1 \%)$ \\
\hline Leukopenia & $15(15.2 \%)$ & $1(1.0 \%)$ \\
\hline Neutropenia & $49(49.5 \%)$ & $32(32.3 \%)$ \\
\hline Thrombocytopenia & $23(23.2 \%)$ & $2(2.0 \%)$ \\
\hline \multicolumn{3}{|l|}{ Gastrointestinal disorders } \\
\hline Abdominal pain & $30(30.3 \%)$ & $2(2.0 \%)$ \\
\hline Diarrhoea & $58(58.6 \%)$ & $13(13.1 \%)$ \\
\hline Intestinal obstruction & $8(8.1 \%)$ & $8(8.1 \%)$ \\
\hline Nausea & $28(28.3 \%)$ & $2(2.0 \%)$ \\
\hline Stomatitis & $52(52.5 \%)$ & $5(5.1 \%)$ \\
\hline Vomiting & $21(21.2 \%)$ & $1(1.0 \%)$ \\
\hline \multicolumn{3}{|c|}{ General disorders and administration site disorders } \\
\hline Asthenia & $65(65.7 \%)$ & $8(8.1 \%)$ \\
\hline \multicolumn{3}{|l|}{ Immune system disorders } \\
\hline Drug hypersensitivity & $9(9.1 \%)$ & $3(3.0 \%)$ \\
\hline Metabolism and nutrition disorders & $37(37.4 \%)$ & $4(4.0 \%)$ \\
\hline Anorexia & $25(25.3 \%)$ & $2(2.0 \%)$ \\
\hline \multicolumn{3}{|c|}{ Musculoskeletal and connective tissue disorders } \\
\hline Back pain & $8(8.1 \%)$ & $2(2.0 \%)$ \\
\hline \multicolumn{3}{|l|}{ Nervous system disorders } \\
\hline Dysaesthesia & $11(11.1 \%)$ & $2(2.0 \%)$ \\
\hline Dysgeusia & $12(12.1 \%)$ & $1(1.0 \%)$ \\
\hline Peripheral neuropathy & $11(11.1 \%)$ & $2(2.0 \%)$ \\
\hline Neurotoxicity & $22(22.2 \%)$ & $2(2.0 \%)$ \\
\hline Paraesthesia & $40(40.4 \%)$ & $6(6.1 \%)$ \\
\hline \multicolumn{3}{|l|}{ Psychiatric disorders } \\
\hline Anxiety & $3(3.0 \%)$ & $2(2.0 \%)$ \\
\hline \multicolumn{3}{|c|}{ Respiratory, thoracic and mediastinal disorders } \\
\hline Pulmonary embolism & $3(3.0 \%)$ & $2(2.0 \%)$ \\
\hline \multicolumn{3}{|c|}{ Skin and subcutaneous tissue disorders } \\
\hline Dry skin & $23(23.2 \%)$ & $4(4.0 \%)$ \\
\hline \multicolumn{3}{|l|}{ Vascular disorders } \\
\hline Deep vein thrombosis & $3(3.0 \%)$ & $2(2.0 \%)$ \\
\hline \multicolumn{3}{|l|}{ Special adverse event categories } \\
\hline Acne-like Rash & $91(91.9 \%)$ & $15(15.2 \%)$ \\
\hline Infusion related reaction $^{a}$ & $14(14.1 \%)$ & $0(0.0 \%)$ \\
\hline Nail toxicity ${ }^{\mathrm{b}}$ & $28(28.3 \%)$ & $6(6.1 \%)$ \\
\hline
\end{tabular}

*Listed are adverse events of any grade occurring in at least $10 \%$ of patients and adverse events of grade 3 or 4 occurring in at least $2 \%$ of patient.

${ }^{a}$ This special event category included the preferred terms infusion related reaction and pyrexia.

${ }^{\mathrm{b}}$ This special event category included the preferred terms nail toxicity and paronychia.

underwent surgery for colorectal liver metastases and a $\mathrm{R} 0$ resection rate was achieved in $18 \%$ of patients. This R0 resection rate is higher than that reported in the cetuximab weekly arm (5\%) and in the cetuximab every second week arm (10\%) of the CECOG trial $[10,19]$.
However, in contrast to the CECOG trial metastases resectability was not a selection criterion in the present study. Therefore, while some patients were initially candidates for surgery, other patients presented with unresectable metastases. In our study, surgical resected 
patients presented a median OS considerably longer than unresected patients. These results confirm the improved prognosis of patients undergoing surgery for colorectal liver metastases.

The toxicity profile of the biweekly administration of cetuximab is also consistent with the known safety profile of the standard weekly cetuximab dosing regimen. The incidence rate of grade 3 or 4 AEs was in line with that reported previously for cetuximab in combination with FOLFOX-4 $[10,18,19]$. Therefore, a higher dose of cetuximab administered on an every-2-weeks basis is not associated with a greater incidence of grade 3 or 4 adverse events. As expected, the most common grade 3 or 4 adverse events were neutropenia and acne-like rash. The high proportion of patients that required at least one cetuximab dose reduction are attributable to dose adjustments planned in case of dose delay of chemotherapy due to haematological toxicity.

\section{Conclusions}

In conclusion, despite the known limitations of a nonrandomised single arm study, our results support the administration of cetuximab in a dosing regimen more convenient for both patients and healthcare providers. The option to synchronise the administration of cetuximab and chemotherapy would reduce the number of administration visits. Such reductions would improve patient's quality of life and simplify treatment administration for healthcare workers. Additionally, the reduction in the number of visits would reduce the costs of treatment of patients with $\mathrm{mCRC}$ without reducing the efficacy previously observed for cetuximab combined with FOLFOX-4.

\section{Abbreviations}

5-FU: 5-fluorouracil; AE: Adverse Event; CEGOG: Central european cooperative oncology group; Cl: Confidence interval; CRC: Colorectal cancer; CT: Computed tomography; CTC-NCl: Common toxicity criteria of the national cancer institute; DCR: Disease control rate; ECOG PS: Eastern cooperative oncology group performance status; EGFR: Epidermal growth factor receptor; FOLFIRI: Irinotecan plus infusional 5-fluorouracil and leucovorin; FOLFOX: Oxaliplatin plus infusional 5-fluorouracil and leucovorin; ITT: Intention to treat population; IV: Intravenous; mCRC: Metastatic colorectal cancer; MRI: Magnetic resonance imaging; ORR: Objective response rate; OS: Overall survival; RDI: Relative dose intensity; RECIST: Response criteria in solid tumours; SD: Standard deviation.

\section{Competing interests}

JFP has participated as a main local investigator in clinical trials across cooperative groups and also as national coordinator of clinical trials across cooperative groups. MS is member of regional and national advisory boards for Galicia and Spain, respectively; has received consulting and educational honoraria from several pharmaceutical companies including Merck, Roche, Amgen and Sanofi; and has participated as main local investigator in clinical trials from Merck, Roche, Amgen, Sanofi, Bayer and Lilly. All other authors declare no conflicts of interests as a consequence of this paper.

\section{Authors' contributions}

JFP and LC conceived the study and its design, coordinated the study group, participated in the quality control of the data, and contributed to the manuscript writing. $C P, G Q, V A, A S, M M, M S$ and ES participated in clinical data collection and reviewed the manuscript. All authors approved the final manuscript.

\section{Acknowledgments}

We thank the participating patients and their families. We also like to thank the ACROSS Group investigators: L. Cirera (Hospital Universitario Mútua Terrassa); J. Fernández-Plana (Hospital Universitario Mútua Terrassa); F. Losa (Hospital General de l'Hospitalet); C. Pericay (Corporación Sanitaria Parc Tauli); A. Salud (Hospital Arnau de Vilanova); M. Gay (Hospital General de Vic); V. Alonso (Hospital Miguel Servet); M. Méndez (Hospital de Móstoles); J. Alfaro (Consorci Hospitalari de Terrassa); P. Vicente (Hospital General de Granollers); G. Quintero (Hospital Xeral-Calde); M. Salgado (Complejo Hospitalario Universitario de Ourense); M. Jorge (Complejo Hospitalario Universitario Xeral-Cies); C. Grande (Hospital de Meixoeiro); J. de la Cámara (Hospital Arquitecto Marcide); E. Falcó (Hospital Son Llàtzer); and E. Saigí (Corporación Sanitaria Parc Tauli). Clinical monitoring: C. Muñoz and M. Nicolau (TFS Develop, Spain). Data management: M. Pircher (TFS Develop, Spain). Statistical analysis: X. Núñez (TFS Develop, Spain). Medical writing: Marta Muñoz-Tudurí, Beatriz del Val, and Emili González-Pérez (TFS Develop, Spain).

\section{Role of the funding source}

The monitoring, statistical analysis and medical writing of this study was supported by Merck KGaA, Darmstadt Germany. Merck KGaA reviewed the manuscript; however, the views and opinions described in the publication do not necessarily reflect those of Merck KGaA who had no involvement in the decision to submit this manuscript for publication.

\section{Author details}

${ }^{1}$ Hospital Universitario Mútua Terrassa, Terrassa, Spain. ${ }^{2}$ Corporación Sanitaria Parc Taulí, Sabadell, Spain. ${ }^{3}$ Hospital Universitario Lucus Augusti (HULA), Lugo, Spain. ${ }^{4}$ Hospital Miguel Servet, Zaragoza, Spain. ${ }^{5}$ Hospital Arnau de Vilanova, Lleida, Spain. ${ }^{6}$ Hospital de Móstoles, Móstoles, Spain. ${ }^{7}$ Complejo Hospitalario Universitario de Ourense, Ourense, Spain. ${ }^{8}$ Corporación Sanitaria Parc Taulí, Sabadell, Spain. ${ }^{9}$ Hospital Universitario Mútua Terrassa, Plaça del Dr. Robert N5, Terrassa, Barcelona 08221, Spain.

Received: 13 May 2014 Accepted: 11 November 2014

Published: 22 November 2014

\section{References}

1. Ferlay J, Steliarova-Foucher E, Lortet-Tieulent J, Rosso S, Coebergh JW, Comber H, Forman D, Bray F: Cancer incidence and mortality patterns in Europe: estimates for 40 countries in 2012. Eur J Cancer 2013, 49(6):1374-1403.

2. Penna C, Nordlinger B: Colorectal metastasis (liver and lung). Surg Clin North Am 2002, 82(5):1075-1090. x-xi.

3. Van Cutsem E, Nordlinger B, Cervantes A, Group EGW: Advanced colorectal cancer: ESMO Clinical Practice Guidelines for treatment. Ann Oncol 2010, 21(Suppl 5):v93-v97.

4. de Gramont A, Figer A, Seymour M, Homerin M, Hmissi A, Cassidy J, Boni C, Cortes-Funes H, Cervantes A, Freyer G, Papamichael D, Le Bail N, Louvet C, Hendler D, De Braud F, Wilson C, Morvan F, Bonetti A: Leucovorin and fluorouracil with or without oxaliplatin as first-line treatment in advanced colorectal cancer. J Clin Oncol 2000, 18(16):2938-2947.

5. Douillard JY, Cunningham D, Roth AD, Navarro M, James RD, Karasek $P$, Jandik P, Iveson T, Carmichael J, Alakl M, Gruia G, Awad L, Rougier P: Irinotecan combined with fluorouracil compared with fluorouracil alone as first-line treatment for metastatic colorectal cancer: a multicentre randomised trial. Lancet 2000, 355(9209):1041-1047.

6. Saltz LB, Cox JV, Blanke C, Rosen LS, Fehrenbacher L, Moore MJ, Maroun JA, Ackland SP, Locker PK, Pirotta N, Elfring GL, Miller LL: Irinotecan plus fluorouracil and leucovorin for metastatic colorectal cancer: Irinotecan Study Group. N Engl J Med 2000, 343(13):905-914.

7. Maughan TS, Adams RA, Smith CG, Meade AM, Seymour MT, Wilson RH, Idziaszczyk S, Harris R, Fisher D, Kenny SL, Kay E, Madi A, Jasani B, James MD, Bridgewater J, Kennedy MJ, Claes B, Lambrechts D, Kaplan R, Cheadle JP, MRC COIN Trial Investigators: Addition of cetuximab to oxaliplatin-based first-line combination chemotherapy for treatment of advanced colorectal cancer: results of the randomised phase 3 MRC COIN trial. Lancet 2011, 377(9783):2103-2114.

8. NCCN clinical practice guidelines in oncology: colon cancer. In http:// www.nccn.org/professionals/physician_gls/f_guidelines.asp. 
9. Bokemeyer C, Bondarenko I, Makhson A, Hartmann JT, Aparicio J, de Braud F, Donea S, Ludwig H, Schuch G, Stroh C, Loos AH, Zubel A, Koralewski P: Fluorouracil, leucovorin, and oxaliplatin with and without cetuximab in the first-line treatment of metastatic colorectal cancer. J Clin Oncol 2009, 27(5):663-671

10. Bokemeyer C, Bondarenko I, Hartmann JT, de Braud F, Schuch G, Zubel A, Celik I, Schlichting M, Koralewski P: Efficacy according to biomarker status of cetuximab plus FOLFOX-4 as first-line treatment for metastatic colorectal cancer: the OPUS study. Ann Oncol 2011, 22(7):1535-1546.

11. Van Cutsem E, Kohne CH, Hitre E, Zaluski J, Chang Chien CR, Makhson A D'Haens G, Pinter T, Lim R, Bodoky G: Cetuximab and chemotherapy as initial treatment for metastatic colorectal cancer. N Engl J Med 2009, 360(14):1408-1417.

12. Van Cutsem E, Kohne CH, Lang I, Folprecht G, Nowacki MP, Cascinu S, Shchepotin I, Maurel J, Cunningham D, Tejpar S: Cetuximab plus irinotecan, fluorouracil, and leucovorin as first-line treatment for metastatic colorectal cancer: updated analysis of overall survival according to tumor KRAS and BRAF mutation status. J Clin Oncol 2011, 29(15):2011-2019.

13. Tabernero J, Pfeiffer $P$, Cervantes A: Administration of cetuximab every 2 weeks in the treatment of metastatic colorectal cancer: an effective, more convenient alternative to weekly administration? Oncol 2008, 13(2):113-119.

14. Tabernero J, Ciardiello F, Rivera F, Rodriguez-Braun E, Ramos FJ, Martinelli E, Vega-Villegas ME, Rosello S, Liebscher S, Kisker O, Macarulla T, Baselga J, Cervantes $A:$ Cetuximab administered once every second week to patients with metastatic colorectal cancer: a two-part pharmacokinetic/pharmacodynamic phase I dose-escalation study. Ann Oncol 2010, 21(7):1537-1545.

15. Martin-Martorell P, Rosello S, Rodriguez-Braun E, Chirivella I, Bosch A, Cervantes A: Biweekly cetuximab and irinotecan in advanced colorectal cancer patients progressing after at least one previous line of chemotherapy: results of a phase II single institution trial. Br J Cancer 2008, 99(3):455-458.

16. Pfeiffer P, Nielsen D, Bjerregaard J, Qvortrup C, Yilmaz M, Jensen B: Biweekly cetuximab and irinotecan as third-line therapy in patients with advanced colorectal cancer after failure to irinotecan, oxaliplatin and 5-fluorouracil. Ann Oncol 2008, 19(6):1141-1145.

17. Roca JM, Alonso V, Pericay C, Escudero P, Salud A, Losa F, Lopez LJ, Guasch I, Mendez M, Quintero-Aldana G, Grande C, Vicente P, Arrivi A, Martin C, Moreno I, García P, Antón I, Constenla M, Yubero A, Cirera L, ACROSS Cooperative Group: Cetuximab given every 2 weeks plus irinotecan is an active and safe option for previously treated patients with metastatic colorectal cancer. Chemotherapy 2010, 56(2):142-146.

18. Eisenhauer EA, Therasse P, Bogaerts J, Schwartz LH, Sargent D, Ford R, Dancey J, Arbuck S, Gwyther S, Mooney M, Rubinstein L, Shankar L, Dodd L, Kaplan R, Lacombe D, Verweij J: New response evaluation criteria in solid tumours: revised RECIST guideline (version 1.1). Eur J Cancer 2009, 45(2):228-247.

19. Brodowicz T, Ciuleanu TE, Radosavljevic D, Shacham-Shmueli E, Vrbanec D, Plate S, Mrsic-Krmpotic Z, Dank M, Purkalne G, Messinger D, Zielinski CC: FOLFOX4 plus cetuximab administered weekly or every second week in the first-line treatment of patients with KRAS wild-type metastatic colorectal cancer: a randomized phase II CECOG study. Ann Oncol 2013, 24(7):1769-1777.

20. Ocvirk J, Brodowicz T, Wrba F, Ciuleanu TE, Kurteva G, Beslija S, Koza I, Papai Z, Messinger D, Yilmaz U, Faluhelyi Z, Yalcin S, Papamichael D, Wenczl M, Mrsic-Krmpotic Z, Shacham-Shmueli E, Vrbanec D, Esser R, Scheithauer W, Zielinski CC: Cetuximab plus FOLFOX6 or FOLFIRI in metastatic colorectal cancer: CECOG trial. World J Gastroenterol 2010, 16(25):3133-3143.

doi:10.1186/1471-2407-14-865

Cite this article as: Fernandez-Plana et al:: Biweekly cetuximab in combination with FOLFOX-4 in the first-line treatment of wild-type KRAS metastatic colorectal cancer: final results of a phase II, open-label, clinical trial (OPTIMIX-ACROSS Study). BMC Cancer 2014 14:865.

\section{Submit your next manuscript to BioMed Central and take full advantage of:}

- Convenient online submission

- Thorough peer review

- No space constraints or color figure charges

- Immediate publication on acceptance

- Inclusion in PubMed, CAS, Scopus and Google Scholar

- Research which is freely available for redistribution

Submit your manuscript at www.biomedcentral.com/submit
Biomed Central 